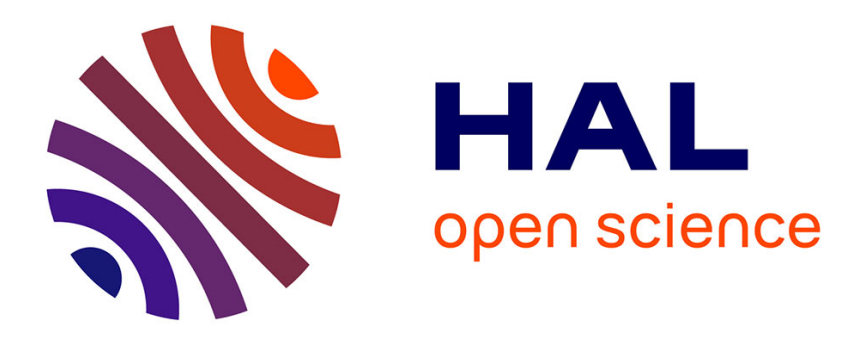

\title{
Modelling of the preheating process of filament tows
}

\author{
B. Lauke, A. Schöne, K. Friedrich
}

\section{To cite this version:}

B. Lauke, A. Schöne, K. Friedrich. Modelling of the preheating process of filament tows. Journal de Physique IV Proceedings, 1993, 03 (C7), pp.C7-1647-C7-1650. 10.1051/jp4:19937257 . jpa-00251896

\section{HAL Id: jpa-00251896 https://hal.science/jpa-00251896}

Submitted on 1 Jan 1993

HAL is a multi-disciplinary open access archive for the deposit and dissemination of scientific research documents, whether they are published or not. The documents may come from teaching and research institutions in France or abroad, or from public or private research centers.
L'archive ouverte pluridisciplinaire HAL, est destinée au dépôt et à la diffusion de documents scientifiques de niveau recherche, publiés ou non, émanant des établissements d'enseignement et de recherche français ou étrangers, des laboratoires publics ou privés. 


\title{
Modelling of the preheating process of filament tows
}

\author{
B. LAUKE, A. SCHÖNE and K. FRIEDRICH* \\ Institute of Polymer Research, Hohe Str. 6, 8010 Dresden, Austria \\ ${ }^{*}$ Institute for Composite Materials, E.-Schrödinger Str., 6750 Kaiserslautern, Germany
}

\begin{abstract}
Filament winding of powder impregnated fibres has been applied to produce composite rings. Important steps in the process are the preheating of the tow within an infrared (IR) preheater. The paper provides results of modelling the heating process of the tow within the preheater. The calculations are focused on the evaluation of the temperature not only at the surface of the tow but also across the whole diameter, i.e. the skin-core effect is investigated.
\end{abstract}

\section{INTRODUCTION}

Among manufacturing methods for continuous-fibre-reinforced thermoplastics the filament winding technique is of special interest, mainly due to its high production speed. The winding process to make polymer matrix-fibre reinforced composites has been applied for many years, mainly on the basis of thermosetting resin matrices. In recent years this technology is increasingly applied for fibre reinforced thermoplastics, see e.g. Wittich and Friedrich /1/.

Different techniques to combine matrix and fibres as basic materials for composite processing are available on the market, e.g. pre-impregnated tapes and tows, materials formed by film stacking, dry powder and meld impregnated fibres. In our paper we discuss the heating of a special material system consisting of glass fibres, polyamide powder between and a polyamide sheath around them (laboratory product by ENICHEM, Italy).

\section{FILAMENT WINDING SET-UP AND MATERIAL}

The filament winding set-up mainly consists of the preheating chamber, the hot air gun at the consolidation point and the heated mandrel. The material runs through a preheater and is than wound on a steel mandrel. Within the preheater of length $L=100 \mathrm{~cm}$ two symmetrically installed infrared radiators are used to heat up the bundle. After leaving the preheater the tow is guided by a roller through an ambient temperature field to the mandrel. To reach good consolidation, the bundle is further heated up at the consolidation point by a hot air gun while being under pressure of a compaction roller. The tow consists of glass-fibres and polyamide (PA12) as powder and surrounding sheet. Additionally, air is enclosed within the tow which has a strong effect on the heat conductivity between the surface and the core region. The tow has a density of 2400 tex $(1$ tex $=1 \mathrm{~g} / 1000 \mathrm{~m})$ with a radius of about $R=1.1 \mathrm{~mm}$. The melt temperature of the polyamide matrix has been determined to be $T_{m}=176^{\circ} \mathrm{C}$. 


\section{PREHEATING OF FILAMENT TOWS}

For process optimisation it is important to know the temperature development during processing. At first the temperature profile within the IR-heater has been determined by the use of a thermo-camera. In Fig. 1 a typical profile is shown for different winding speeds. It becomes clear that the melting temperature of the polymer on the surface of the thread is reached at winding speeds of $v=1.0$ and $2.5 \mathrm{~cm} / \mathrm{s}$. The tow material is rather inhomogeneous and above all it consists of a high volume percent of air: $\varphi_{\mathbf{a}}=0.67$. Therefore it will take a certain time until also the powder in the centre will reach the melting temperature. The shown behaviour results from thermodynamics and two effects may be responsible for it. After the melt temperature is reached, heat energy is consumed during melting of the polymer powder. This results in the fact that the surface temperature does not increase furthermore and that the powder melts already within the preheating chamber. This effect is superimposed by the change in the heat convection process. In the first part of the chamber the air surrounding the is warmer than the tow itself, at a certain point, however, this relation changes, consequently heat is transported to the air.

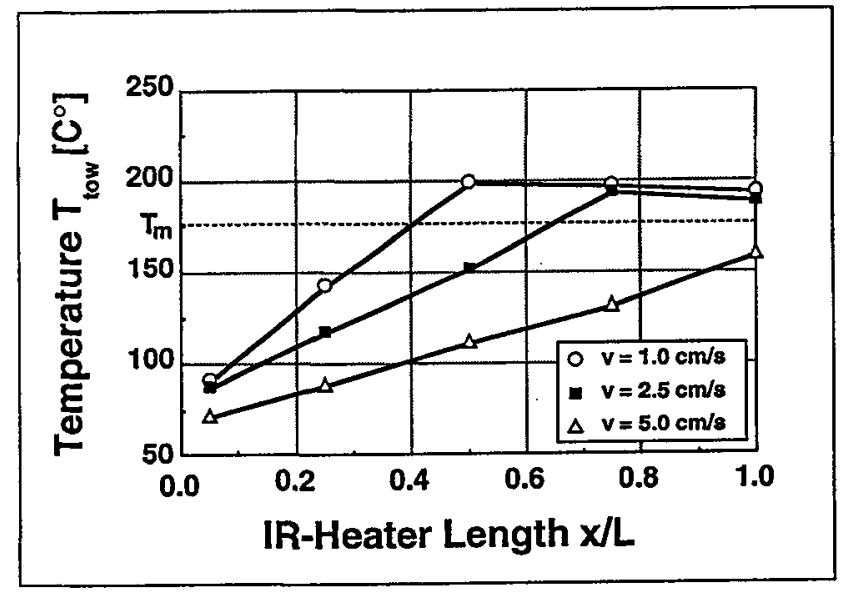

Figure 1: Temperature development on the polymeric sheath surface within the IR-heater, IRpower: $\dot{Q}=9.6 \mathrm{~kW}$.

It is difficult to determine the inner temperature of the tow experimentelly. That's why the following model to calculated the temperature distribution is applied.

\section{MODELLING OF THE PREHEATING PROCESS}

The technological set-up with three heating (cooling) zones is reduced now to the process of heat transition to the composite preform within the preheating chamber $\left(0 \leq x \leq L_{1}\right)$ with an air temperatures of $T_{a}$.

\section{Basic Assumptions}

To get the axial and radial temperature profiles the energy equation has to be solved. For this the following assumptions are made:

(a) steady-state temperature field, i.e. the temperature profile is only a function of the axial and radial co-ordinates and does not depend on time: $T(x(t), r(t), t)=T(x(t), r(t))$; 
(b) axisymmetrical temperature distribution;

(c) negligible axial heat conduction;

(d) mean values of heat conductivity, specific heat and density of the tow.

\section{Governing Equations}

With the above given conditions the heat flow equation can be set up as (cf. Andrews $/ 2 /$ )

$$
\frac{1}{r} \frac{\partial}{\partial r}\left(r \frac{\partial T}{\partial r}\right)=\frac{\bar{\rho} \cdot \bar{c}_{p} \cdot v}{\bar{\lambda}} \frac{\partial T}{\partial x}
$$

where $x, r=$ axial and radial coordinates, $\bar{\lambda}=$ mean heat conductivity, $\bar{\rho}=$ mean density, $\bar{c}_{p}=$ mean heat capacity, and $v=$ tow velocity with $\bar{\lambda}=0.06352 \mathrm{~W} / \mathrm{mK}, \bar{\rho}=650.15 \mathrm{~kg} / \mathrm{m}^{3}$, and $\bar{c}_{p}$ $=1229.3 \mathrm{~J} \mathrm{~K}^{-1} \mathrm{~kg}^{-1}$.

The boundary conditions for this differential equation are given by the temperature at the preheater entrance $x=0$ :

$$
T(x=0, r)=T_{0}
$$

and the heat transition by radiation and convection at the tow surface $(r=R)$ :

$$
\dot{q}=\bar{\lambda} \frac{\partial T}{\partial r}=\dot{q}_{r}+\dot{q}_{c}
$$

These energies per time and area are given by

$$
\begin{aligned}
& \left.\dot{q}_{r}=\varepsilon c_{s}\left[\Theta\left(T_{i r}{ }^{4}-T^{4}\right)\right]+(1-\Theta)\left(T_{a}^{4}-T^{4}\right)\right] \\
& \dot{q}_{c}=\lambda_{a} N u\left(T_{a}-T\right) / 2 R
\end{aligned}
$$

where $T_{a}$ is the temperature and $\lambda_{a}$ the heat conductivity of the tow surrounding air, $\mathrm{T}_{\text {ir }}=$ temperature of the IR-radiators, Nu= NUSSELT-number, $\Theta=$ the radiation angle, $c_{\mathrm{s}}=$ radiation constant, with $c_{s}=5.66910^{-8} \mathrm{~W} / \mathrm{m}^{2} / \mathrm{K}^{4}$, and $\varepsilon=0.8$ as the emission coefficient.

The boundary condition (4) makes the problem nonlinear and complicated. To simplify the solution a linearisation of this equation is proposed herein in the form:

$$
\dot{q}=\lambda_{a} N u_{e f f}\left(T_{a, \text { eff }}-T\right) / 2 R
$$

with the physical meaning that the surrounding of the tow - characterised by IR-radiation and convection heat - is replaced by an effective convection problem. The validity of this approximation could be proved with the one dimensional heat flow equation.

A solution of this problem has been given by Andrews $/ 2 /$ for the melt spinning process with fibre cooling. This solution is used now for the analogous heating problem:

$$
T(x, r)=T_{a, e f f}+\sum_{i} B_{i} \cdot J_{0}\left(p_{i} \cdot \frac{r}{R}\right) \cdot \exp \left(-\frac{p_{i}^{2} \cdot \bar{\lambda} \cdot x}{R^{2} \cdot v \cdot \bar{\rho} \cdot \vec{C}_{p}}\right)
$$


The eigenvalues $p_{i}$ are provided by the boundary condition (6) to be:

$$
p_{i}=\frac{\lambda_{a} \cdot N u_{\text {eff }} \cdot J_{0}\left(p_{i}\right)}{2 \cdot \bar{\lambda} \cdot J_{1}\left(p_{i}\right)}
$$

and the coefficients $B_{j}$ are determined with the initial condition (3) as:

$$
B_{i}=\frac{N u_{e f f} \cdot \lambda_{a} \cdot\left(T_{0}-T_{a, e f f}\right)}{\bar{\lambda} \cdot J_{0}\left(p_{i}\right) \cdot\left(p_{i}^{2}+\left(\frac{N u_{\text {eff }} \cdot \lambda_{a}}{2 \cdot \bar{\lambda}}\right)^{2}\right)}
$$

Inserting these relations into eqn (7) the temperature profile of the tow at the skin $(r=R)$ and at the core $(r=0)$ can be determined. For a special parameter set (IR-temperature: $T_{i r}=600{ }^{\circ} \mathrm{C}$, volume fractions: $v_{f}=0.2, v_{m}=0.13, v_{a}=0.67$, radiation angle: $\Theta=0.12$ ) the temperatures of the core and the skin along the preheater are shown in Fig. 2.

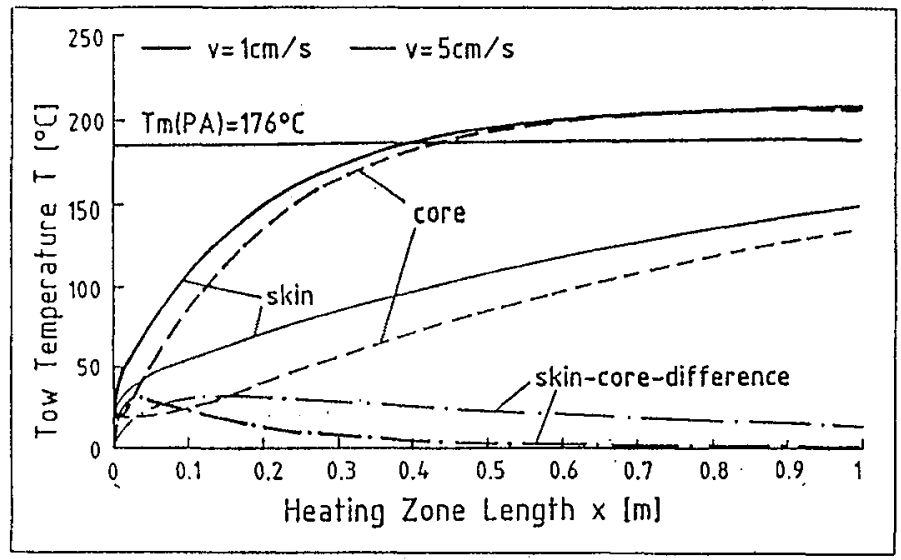

Figure 2: Temperature profile of the tow surface and core and their difference along the preheater length

For a tow speed of $v=5 \mathrm{~cm} / \mathrm{s}$ the melt temperature of polyamide is not reached and the temperature difference between skin and core is still high at the end of the chamber. If the tow remains longer within the chamber as for $v=1 \mathrm{~cm} / \mathrm{s}$ than the skin -core effect can be neglected already in the middle of the chamber.

\section{REFERENCES}

1 Wittich, H., Friedrich, K., "Continuous Consolidation of Thermoplastic Impregnated Long Fibre Tapes into High Performance Composite Laminates", Proc. 22nd AVK-Conference, Mainz, Germany, May 1989.

2 Andrews, F. H., "Cooling of a spinning thread-line", British Journ. of Appl. Physics, Vol 10 (1959), p.39.

\section{ACKNOWLEDGEMENT}

The financial support of the Deutsche Forschungsgemeinschaft (DFG-FR 675-4-2) for this study is gratefully acknowledged. Further thanks are due to ENICHEM, Milano, Italy, for their free material supply. 